\title{
Effect of cultivar $x$ ozone treatment interaction on the total polyphenols content and antioxidant activity of globe artichoke
}

\author{
Sara Lombardo, Gaetano Pandino, Cristina Restuccia, Giuseppe Muratore, \\ Fabio Licciardello, Rosario Paolo Mauro, Roberto Pesce, Giovanni Mauromicale \\ Dipartimento di Agricoltura, Alimentazione e Ambiente, Università di Catania, Italy
}

\begin{abstract}
Two globe artichoke cultivars (Violet de Provence and Apollo) were harvested at an experimental field in Sicily, immediately washed with ozonised water and stored in: i) normal atmosphere; ii) ozone-enriched atmosphere for 3 days and for the last 4 days in normal atmosphere; iii) ozone-enriched atmosphere for 7 days. A control (samples unwashed and stored at room temperature) was also investigated. The effect of $\mathrm{cul}$ tivar $x$ ozone treatment interaction on water content losses, total polyphenols content and antioxidant activity was evaluated after 0,3 and 7 days of storage. Washing with ozonised water and storage under $\mathrm{O}_{3^{-}}$ enriched atmosphere allowed higher water retention compared with the control, especially for Violet de Provence. After 3 days of storage in ozone-enriched atmosphere, on average of cultivars, the total polyphenols content and antioxidant activity increased by $11.7 \%$ and $5.5 \%$, respectively. By contrast, after further 4 days of storage in ozonised atmosphere, Apollo and Violet de Provence displayed a significant reduc-
\end{abstract}

Correspondence: Sara Lombardo, Dipartimento di Agricoltura, Alimentazione e Ambiente (Di3A), Università di Catania, via Valdisavoia 5, 95123 Catania, Italy.

Tel.: +39.095.234421 - Fax: +39.095 .234449 .

E-mail: sara.lombardo@unict.it

Key words: Antioxidant activity; cultivar; globe artichoke; ozone; total polyphenols; water content loss.

Acknowledgements: this research was a part of Innovazione di processo e di prodotto per una cinaricoltura sostenibile project, funded by P.S.R. Sicilia 2007-2013 Misura 124 Cooperazione per lo sviluppo dei nuovi prodotti, processi e tecnologie nei settori agricolo e alimentare e in quello forestale. The authors are grateful to Mr. Angelo Litrico for his excellent agronomical assistance and to Violetto Ramacchese Cooperativa Agricola company for hosting the trials.

Conference presentation: SIA XLIII Congress, Pisa, 2014.

Received for publication: 28 November 2014.

Revision received: 3 March 2015.

Accepted for publication: 7 March 2015.

(C) Copyright S. Lombardo et al., 2015

Licensee PAGEPress, Italy

Italian Journal of Agronomy 2015; 10:634

doi:10.4081/ija.2015.634

This article is distributed under the terms of the Creative Commons Attribution Noncommercial License (by-nc 3.0) which permits any noncommercial use, distribution, and reproduction in any medium, provided the original author(s) and source are credited. tion in their level of total polyphenols and aantioxidant activity. The exposure of globe artichoke heads to an ozone-enriched atmosphere should not exceed 3 days aimed at preserving their high nutritional value, with special emphasis on total polyphenols content.

\section{Introduction}

Over the years, major attention has been focused on food safety and quality due to the increasing cases of foodborne diseases. Among the technologies adopted, ozonation has been recently proposed to extend the shelf-life of fruits and vegetables, ensuring the reduction of their microbial load (Zhang et al., 2005). Due to its strong oxidising capacity and spontaneous decomposition to non-toxic products, ozone $\left(\mathrm{O}_{3}\right)$ is, at the same time, an effective and safe disinfectant which has been increasingly recommended in the horticultural industry as alternative to chlorine-based agents (Kim et al., 1999; Zhang et al., 2005). However, ozone, applied as gas or ozonated water, may affect quality in relation to the sensitivity of the vegetable (Skog and Chu, 2001). For globe artichoke [Cynara cardunculus var. scolymus (L.) Fiori], which is very perishable and sensitive to water content loss, ozone application during postharvest may reduce the microbial population and nutritional quality loss of the produce, on condition that specific postharvest treatments are considered for each cultivar (Restuccia et al., 2014). However, the effects of ozone application on the quality of globe artichoke deserves further investigation also with the aim of preserving the level of antioxidant compounds. Indeed, globe artichoke heads are an excellent source of polyphenols (Lombardo et al., 2012, 2013; Pandino et al., 2011, 2012a, 2012b), which play important roles: i) as scavengers against the harmful free radicals derived from the oxidative stress and implicated in several disorders; ii) on the product sensory characteristics, such as colour, bitterness and aroma; iii) on the processing suitability of the heads, being substrates for oxidative enzymatic and non-enzymatic browning reactions (Lattanzio et al., 1994). Therefore, in the present work the effect of postharvest treatments with ozone on water content loss, total polyphenols content and antioxidant activity of globe artichoke whole heads was studied. In particular, we investigated how the interruption of ozone insufflation in cooling chamber could influence product shelf-life.

\section{Materials and methods}

Plant material, experimental field and management practices

Experimental field trial was conducted during the 2012-2013 growing season at a farm located in Ramacca $\left(37^{\circ} 23 \mathrm{~N}, 14^{\circ} 41 \mathrm{E}, 144200 \mathrm{~m}\right.$ asl) in the Catania Plain (Sicily, Italy), which is a typical area for the globe artichoke cultivation. The local climate is semiarid-Mediterranean, with 
mild winters and hot-rainless summers. Two globe artichoke cultivars were studied: Violet de Provence, a reflowering multiclone cultivar actually widespread in all the Mediterranean Basin, producing elongated green heads with purple shades, and Apollo, a Romanesco type cultivar, characterised by spherical shaped heads with deep violet bracts. These cultivars were arranged in a randomised block experimental design with four replicates, consisting of 50 plants per plot. Semi-dormant offshoots (ovoli) were manually planted in August, adopting a planting density of 1.0 plant $\mathrm{m}^{-2}$. A typical fertilisation programme $\left(200 \mathrm{~kg} \mathrm{~N}, 80 \mathrm{~kg} \mathrm{P}_{2} \mathrm{O}_{5}\right.$ and $100 \mathrm{~kg} \mathrm{~K} \mathrm{~K}_{2} \mathrm{per} \mathrm{ha}$ ) was applied. Drip irrigation was carried out during the summer, when the accumulated daily evaporation (measured from an unscreened class A-Pan evaporimeter near the crop) reached $35 \mathrm{~mm}$. Weed and pest control followed standard commercial practice. Lateral shoots were removed twice in November and mid-February, having only one shoot per plant.

\section{Head harvest, postharvest treatments and sampling}

At least 300 disease-free heads for each cultivar were harvested at the end of March, at marketable stage (Mauromicale and Ierna, 2000), and directly transported from the experimental field to Violetto Ramacchese Cooperativa Agricola, an industrial company located in Ramacca (Eastern Sicily, Italy), kept at room temperature and processed within 24 h. Briefly, about 60 heads, for each postharvest treatment, were prepared by removing the leaves and cutting the floral stems to $5 \mathrm{~cm}$ in length and packaged into perforated plastic boxes according to Italian commercial practices. Sixty unwashed heads were stored at room temperature throughout the experiments (control), whereas the remaining were immersed in ozonised tap water (for $5 \mathrm{~min}$ ), drained and stored in a dark cooling chamber (with an internal volume of $165 \mathrm{~m}^{3}$, maintained at $4 \pm 1^{\circ} \mathrm{C}$ and $90 \%$ of relative humidity) under the following conditions: i) in normal atmosphere; ii) in an ozone-enriched atmosphere for 3 days and in normal atmosphere for the last 4 days; iii) in an ozone-enriched atmosphere for 7 days. A more detailed description of both the system of washing with ozonised water and storage under $\mathrm{O}_{3}$-enriched atmosphere, provided by SAIM Service s.r.l. (Latina, Italy), was already reported by Restuccia et al. (2014). Sub-samples (15 heads) of each postharvest treatment and cultivar were transported to University of Catania laboratories under refrigerated conditions for subsequent evaluation of antioxidants content on the day of processing and after 3 and 7 days of storage.

\section{Water content losses determination}

At each sampling, five globe artichoke heads, for each cultivar and postharvest treatment were selected, weighted and then oven-dried at $65^{\circ} \mathrm{C}$ (Binder, Milan, Italy) until constant weight, in order to determine the water content (WC) and to compute its losses (WCL), expressed as $\%$ of the initial value, throughout the experiments.

\section{Chemical analyses}

Five whole heads per postharvest treatment, cultivar and storage time were freeze-dried (Christ freeze drier, Osterode am Harz, Germany) and stored at $20^{\circ} \mathrm{C}$ until chemical analyses. The total polyphenols content (TPC) was determined according to Restuccia et al. (2014), using the Folin-Ciocalteu assay and chlorogenic acid as standard. The antioxidant activity (AA) was evaluated as percentage inhibition of 1,1-diphenyl-2picrylhydrazyl radical (Brand-Williams et al., 1995).

All the reagents and solvents, of analytical or high-performance liquid chromatography grade, were purchased from Sigma-Aldrich (Milan, Italy). All the chemical analyses were performed in triplicate.

\section{Statistical analysis}

Bartlett's test was used to test the homoscedasticity, following which the data from each storage time were subjected to analysis of variance (ANOVA) as a factorial combination of postharvest treatment (4) $x$ cultivar (2). Means were separated by Duncan's multiple range test, when the $F$-test was significant. Percent values were transformed to $\arcsin \sqrt{ } \mathrm{x}$ (Bliss transformation) prior to analysis and then subjected to ANOVA; untransformed data were reported and discussed. Statistical analysis was performed by the statistical package SPSS® Statistics 13.0 (Armonk, NY, USA).

\section{Results}

The initial values for WC, TPC and AA are reported in Table 1. The unwashed heads stored for 7 days at room temperature achieved a significantly higher WCL (2.4\% and 2.6\% for Apollo and Violet de Provence, respectively) than that reported for the other postharvest treatments (from $0.8 \%$ to $1.4 \%$; Figure 1A). After 3 or 7 days of cold storage, independently from storage conditions and cultivar, samples washed in ozonated water resulted in lower WCL as compared to the control (Figure 1A). Moreover, after 3 days of cold storage in ozone-enriched atmosphere, TPC increased by $13.6 \%$ and $9.8 \%$ in Apollo and Violet de Provence heads, respectively. The ozone injection for further 4 days significantly reduced $(-11 \%$ and $-18.9 \%$, respectively for Apollo and Violet de Provence) the TPC compared with the same batch stored for 3 days. The interruption of ozone injection in the cooling chamber preserved the TPC compared with the injection of the gas up to the $7^{\text {th }}$ day of storage (32.9 vs $27.8 \mathrm{~g} \mathrm{~kg}^{-1}$ of dry matter, on average of cultivar). Finally, after both 3 and 7 days of storage the control achieved the lowest TPC (Figure 1B). A similar trend was observed for the antioxidant activity (Figure 1C). In particular, for both cultivars, the interruption of ozone insufflation in the cooling chamber after 3 days ensured a higher AA than the extended injection of this gas for 7 days. The unwashed heads stored at room temperature showed the lowest AA for both Apollo and Violet de Provence (61.6\% and 58.7\%, respectively) (Figure 1C). Finally, a positive correlation across the postharvest treatments was found between TPC and AA, after both 3 days $\left(\mathrm{r}=0.739^{* *}\right)$ and 7 days $\left(\mathrm{r}=0.756^{* * *}\right)$ of cold storage (data not shown).

\section{Discussion}

In the present work, we investigated the effect of postharvest treatments with an ozone-enriched atmosphere (for 3 or 7 days) on water content losses, total polyphenols content and antioxidant activity of two globe artichoke cultivars widely cropped. In particular, the effect of ozone application on TPC is relevant since these substances play a significant role in the detoxification process versus the reactive oxygen species (ROS), which could derive from ozone decomposition (Alothaman et al., 2010). The observed increase in the TPC of the whole head up to the $3^{\text {rd }}$

Table 1. Water content, total polyphenols content and antioxidant activity of whole globe artichoke heads prior to processing.

\begin{tabular}{lccc} 
Cultivar & WC & TPC & AA \\
& $(\%)$ & $\left(\mathrm{g} \mathrm{k}^{-1}\right.$ DM) & (DPPH \% inhibition) \\
Apollo & $86.2^{\mathrm{a}}$ & $28.0^{\mathrm{b}}$ & $65.0^{\mathrm{b}}$ \\
Violet de Provence & $86.1^{\mathrm{a}}$ & $32.6^{\mathrm{a}}$ & $66.0^{\mathrm{a}}$ \\
\hline
\end{tabular}

WC, water content; TPC, total polyphenols content; DM, dry matter; AA, antioxidant activity; DPPH, 1,1diphenyl-2-picrylhydrazyl. a,b In each column values followed by different letters are significantly different at $\mathrm{P} \leq 0.05$ by Duncan's multiple range test. 
day of storage may be due to the activation of the phenylalanine ammonia-lyase, the key enzyme in the polyphenols biosynthesis, during cold storage of globe artichoke (Lattanzio et al., 1994). In addition, the increased TPC may be caused by cell wall modification that occurred in plant tissues during ozone exposure and increased the polyphenols extractability through the release of some conjugated phenolic compounds present in the cell wall (Alothaman et al., 2010). This could also explain the increase in the antioxidant activity of the samples stored in $\mathrm{O}_{3}$-enriched atmosphere. By contrast, a prolonged exposure (more than 3 days) to gaseous ozone caused, especially in Violet de Provence, a significant degradation of polyphenols, which may be partly attributed to the scavenging activity of these phytochemicals versus ROS (Alothaman et al., 2010). Nevertheless, the antioxidant activity for samples stored
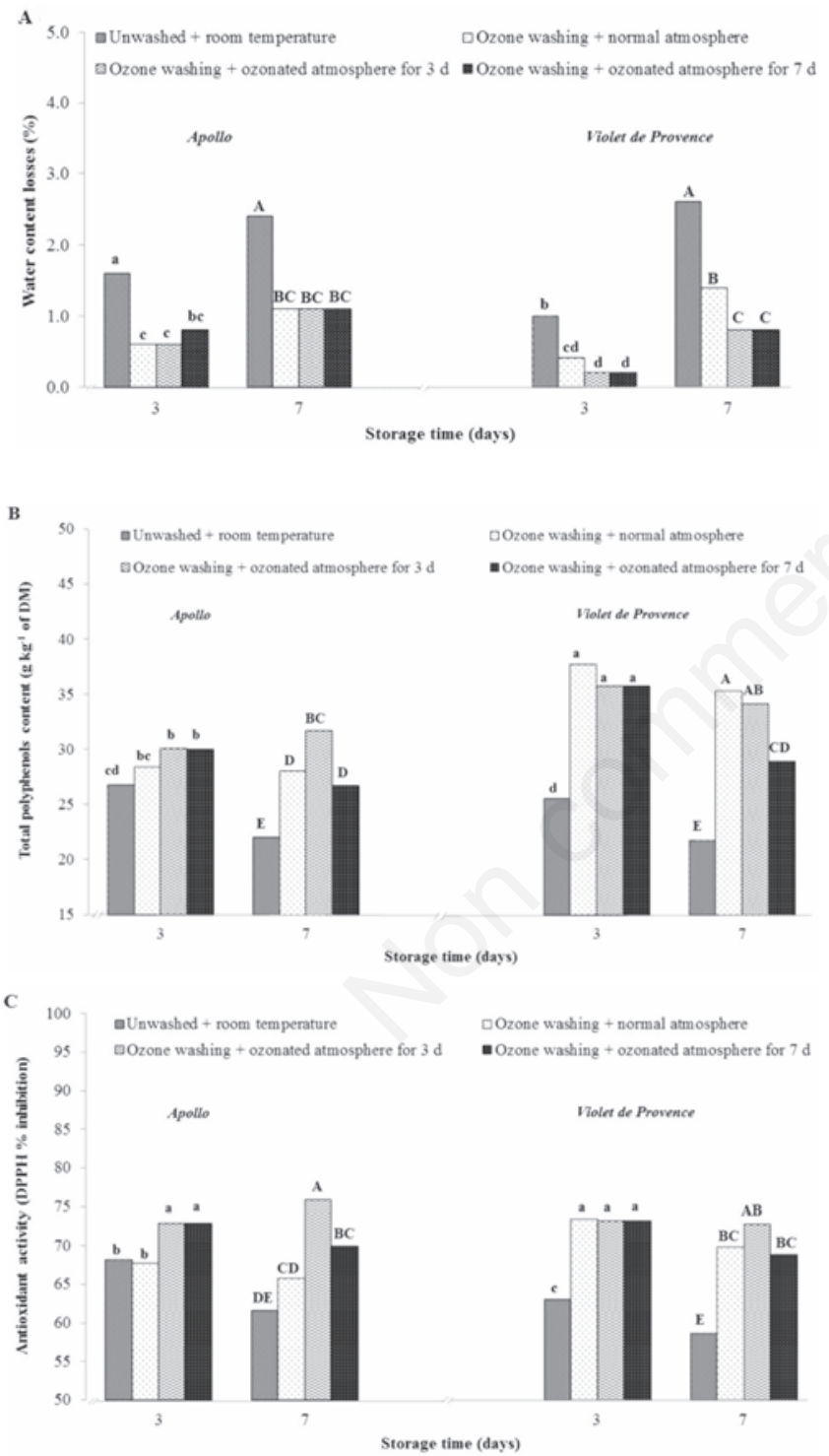

Figure 1. Effect of cultivar $\times$ ozone treatment interaction on water content losses (A), total polyphenol content (B) and antioxidant activity (C) of whole globe artichoke heads during cold storage. For each parameters, values followed by different letters and within the same storage time are significantly different at $\mathbf{P} \leq \mathbf{0 . 0 5}$ by a Duncan's multiple range test. $\mathrm{DM}$, dry matter; DPPH, 1,1-diphenyl-2-picrylhydrazyl. under $\mathrm{O}_{3}$-enriched atmosphere was higher than the control and this indicates that the studied cultivars were able to control oxidative damage due to ozone exposure. In addition, water content losses were significantly reduced by ozone washing, independently from the storage conditions. Particularly, after both 3 and 7 days of cold storage, the rate of water content loss in Violet de Provence was lower in samples stored in ozoneenriched atmosphere. This is important since many vegetables undergo a deterioration in their turgidity as a result of a stress (as ozone is) induced in the tissues.

In conclusion, our findings demonstrate that storage in ozonised atmosphere up to 3 days might preserve the content of polyphenols and antioxidant activity of globe artichoke heads while maintaining product turgidity. The extension of quality retention, with special emphasis on water and total polyphenols content, could be important for globe artichoke heads destined to both fresh market and food industry. However, further studies are necessary to investigate other factors (e.g., different exposure time to ozone, harvest time), which may improve quality of globe artichoke heads.

\section{References}

Alothman M, Kaur B, Fazilah A, Bhat R, Karim AA, 2010. Ozone-induced changes of antioxidant capacity of fresh-cut tropical fruits. Innov. Food Sci. Emerg. Technol. 11:666-71.

Brand-Williams W, Cuvelier ME, Berset C, 1995. Use of a free radical method to evaluate antioxidant activity. Lebensm. Wiss. Technol. 22:25-30.

Kim JG, Yousef AE, Dave S, 1999. Application of ozone for enhancing the microbiological safety and quality of foods: a review. J. Food Prot. 62:1071-87.

Lattanzio V, Cardinali A, Di Venere D, Linsalata V, Palmeri S, 1994. Browning phenomena in stored artichoke (Cynara scolymus L.) heads or chemical reactions? Food Chem. 50:1-7.

Lombardo S, Pandino G, Mauromicale G, 2013. Total polyphenol content and antioxidant activity among clones of two Sicilian globe artichoke landraces. Acta Hort. 983:95-101.

Lombardo S, Pandino G, Mauromicale G, Carle R, Knödler M, Schieber A, 2012. New seed propagated cultivars of globe artichoke suitable for processing uses. Acta Hort. 942:139-46.

Mauromicale G, Ierna A, 2000. Characteristics of heads of seed-grown globe artichoke [Cynara cardunculus L. var. scolymus (L.) Fiori] as affected by harvest period, sowing date and gibberellic acid. Agronomie 20:197-204.

Pandino G, Lombardo S, Mauromicale G, 2011. Mineral profile in globe artichoke as affected by genotype, head part and environment. J. Sci. Food Agr. 91:302-8.

Pandino G, Lombardo S, Mauromicale G, Williamson G, 2012a. Characterization of phenolic acids and flavonoids in leaves, stems, bracts and edible parts of globe artichokes. Acta Hort. 942:413-7.

Pandino G, Lombardo S, Williamson G, Mauromicale G, 2012b. Polyphenol profile and content in wild and cultivated Cynara cardunculus L.: a review. Ital. J. Agron. 7:254-61.

Restuccia C, Lombardo S, Pandino G, Licciardello F, Muratore G, Mauromicale G, 2014. An innovative combined water ozonisation $/ \mathrm{O}_{3^{-}}$ atmosphere storage for preserving the overall quality of two globe artichoke cultivars. Innov. Food Sci. Emerg. Technol. 21:82-9.

Skog LJ, Chu CL, 2001. Effect of ozone on qualities of fruits and vegetables in cold storage. Can. J. Plant Sci. 81:773-8.

Zhang L, Zhaoxin L, Zhifang Y, Xiang G, 2005. Preservation of fresh-cut celery by treatment of ozonated water. Food Control 16:279-83. 